\title{
3 Research Square \\ Predictors and Incidence of Extubation Failure Post Modified Blalock Taussig Shunt in Infants
}

Mohammed Al Ghafri ( $\triangle$ mhghafri@hotmail.com )

The Royal Hospital https://orcid.org/0000-0003-1193-7643

\section{Safa Al Hadhrami}

Oman Medical Speciality Board

\section{Hamid Al Badi}

Oman Medical Speciality Board

\section{Research}

Keywords: extubation failure modified Blalock Taussig shunt, congenital heart disease

Posted Date: March 24th, 2021

DOl: https://doi.org/10.21203/rs.3.rs-331435/v1

License: (1) This work is licensed under a Creative Commons Attribution 4.0 International License. Read Full License 


\section{Abstract}

Objectives: To identify the characteristics of infants with extubation failure post Modified Blalock-Taussig Shunt (MBTS) and to determine the incidence and predictors of extubation failure in this group of infants and to compare it with the international figures.

Methods: A single-center retrospective cohort study of infants $<1$ year of age who underwent MBTS at the pediatric cardiac intensive care unit at Royal Hospital, Oman, from January 2010 to December 2019. We excluded infants who died before extubation, infants with missing data, and infants who underwent another surgical intervention before extubation. Ethical approval was obtained from the scientific research committee at the Royal Hospital. All categorical variables were presented as numbers and percentages. Analyses were performed using SPSS version 25.

Results: A total of 146 infants were included in the study. Extubation failure occurred in 27 (18.5\%) patients. Among those who failed extubation, 18 (66.7\%) patients were ventilated before the surgery with statistically significant $p$-value of 0.019 . A systolic blood pressure (SBP) $\leq 50$ th percentile was associated with extubation failure. Infants with extubation failure had longer intensive care unit length of stay and longer hospital length of stay. Severe respiratory distress and hemodynamic instability were the two main reasons for re-intubation.

Conclusions: The lower incidence rate (18.5\%) for extubation failure might indicate higher quality performance of our institution. Prolonged mechanical ventilation, requirements for escalation of inotropes, and SBP $\leq$ 50th percentile might be as predictors for extubation failure in infants post MBTS. Extubation failure is associated with longer intensive care unit and hospital admission.

\section{Introduction}

Infants with congenital heart diseases are ill group of patients requiring mechanical ventilation and long intensive care unit stays secondary to the complex cardiopulmonary complications $(1,2)$. Systemic to pulmonary shunting provides palliative treatment for most of the cyanotic congenital heart diseases, ranging from simple Tetralogy of Fallot (TOF) and pulmonary atresia (PA) to complex univentricular hearts with major associated surgical problems.

Modified Blalock Taussig shunt (MBTS) is the mainstay palliative surgery, in which pulmonary blood flow shunting is created to alleviate cyanosis and improve exercise tolerance in the patients. This shunt is achieved through interposing a graft between the innominate or subclavian artery and the ipsilateral pulmonary artery (PA) $(3,4)$. The concept is simple, yet the operation is associated with significant morbidity and mortality rate. Reports have shown mortality in patients with single ventricle of about $15 \%$ compared to $3-5 \%$ in those with biventricular anatomy, as they have more cardiopulmonary complication and longer need of intensive care stay $(5,6)$. 
Although, postoperative cardiac surgeries management in intensive unit went through multiple levels of improvement in term of duration of ventilation and the decision of extubation, complications remained high. With Modified surgical techniques and intensive care unit advances management, early extubation has been more common in children after cardiac surgery $(7,8,9)$.

Changing from mechanical ventilation to room air for the children after cardiac surgery is a major clinical decision. The recognition of who can be successfully extubated is a complex decision-making process with serious outcomes that includes the risk of extubation failure and the need of reintubation $(10,11,13)$. Early and untimely extubation carries high risk for extubation failure and a need for re-intubation $(7,10$, $11,12)$.

Extubation failure is commonly seen after prolonged mechanical ventilation in $22-28 \%$ of premature babies, $15-20 \%$ of critically ill children, and $10 \%$ of children after cardiac surgery (8-13). Children failing extubation require emergent re-intubation, which can lead to significant unnecessary airway trauma, hemodynamic instability and increased risk of infections. Consequently, these will lead to prolonged duration of mechanical ventilation and increase length of stay in intensive care unit $(14,15)$.

Existing literature on extubation failure in infants with modified Blalock-Taussig shunt is currently limited to heterogeneous patient populations undergoing uncomplicated repairs $(16,17,18)$. In addition, we don't have local or even Middle East data about extubation failure in this group of infants.

This study was undertaken to investigate the incidence and the predictors of extubation failure in infants with modified Blalock Taussig shunt-dependent pulmonary blood flow at the Royal hospital, Oman.

\section{Aim and Objectives:}

This study aims to evaluate the predictors and the incidence of extubation failure post BT shunt in pediatric cardiac ICU at the Royal Hospital from January 2010 till December 2019 and to come up with local practical guidelines.

The objectives of the study were to identify the characteristics of patients with extubation failure post BT shunt in pediatric cardiac ICU, to calculate the incidence of extubation failure in this group of patients and to identify the most common predictors of extubation failure post BT shunt and compare it with the international figures.

\section{Methods}

Setting and patients:

We performed a single-center retrospective cohort study in intensive care unit at the Royal Hospital from January 2010 to December 2019. Medical ethics and scientific research committee at the Royal Hospital approved the study. The study included all infants (less than one year of age) who underwent modified Blalock-Taussig shunt at the Royal Hospital. Exclusion criteria included infants died before extubation, 
infants with uncompleted data in the hospital electronic system and infants requiring other surgical intervention before extubation as demonstrated in Fig 1. We collected the potential patients list from the departmental saved database.

\section{Airway management:}

Our cohort of patients were intubated with 3-mm, 3.5-mm or 4.0-mm cuffed endotracheal tube and ventilated. All patients were ventilated according to their clinical presentation post modified BlalockTaussig shunt in intensive care unit, but the ventilator mode was switched to weaning mode for at least 30 minutes before extubation. Tracheal extubation was performed following a standardized protocol for ventilator weaning in our unit. All patients in our cohort were extubated to non-invasive ventilation (bilevel positive airway pressure or continuous positive airway pressure) or to nasal cannula with either high or low flow oxygen.

The following respiratory parameters were monitored before extubation: respiratory rate, adequacy of chest wall excursion, and use of accessory respiratory muscles and hemodynamic changes: heart rate, blood pressure, transdermal oxygen saturation and blood gas parameters. The sedation and analgesic weaned off before extubation.

Extubation failure was considered when infants required re-intubation within 72 hours post extubation if they met one or more of the following criteria:

(1) Showing clinical signs of respiratory distress, as presented with increase in respiratory rate, severe chest wall excursion, and use of accessory respiratory muscles.

(2) Hypercarbia and/or hypoxemia from the baseline value for the patient.

(3) Hemodynamic instability, with reduce in blood pressure and requirement of escalation of inotropes.

(4) Cardiorespiratory arrest.

(5) Inability to maintain adequate airway patency owing to neurological impairment.

Study definitions and data collection:

As the study criteria, failed extubation was defined as the need for reintubation within 72 hours of an extubation attempt.

For each patient, the following variables were collected: age, gender, weight, prematurity, associated diagnoses - chronic lung disease, chromosomal abnormality (Trisomy 21 or Di George) - and status of intubation before surgery.

The intra-operative variables collected included: date of surgery, urgency of the surgery, single ventricle or bi-ventricle, size of the shunt, site of the shunt, site of the surgery, duration of open chest, the need of 
cardiopulmonary bypass and the duration, the need of ECMO and the type of ET tube.

The post-operative variables collected included: first lactate level upon arrival to ICU, inotropic score upon arrival, the need to escalate inotropes, extracorporeal membrane oxygenation and partial pressure of oxygen in the first blood gas at ICU.

Post-operative complications were observed and collected including: need for dialysis, sepsis, atelectasis/ pneumonia, pleural effusion, chylothorax, diaphragmatic paralysis, necrotizing enterocolitis, vocal cord paralysis, use of inhaled nitric oxide, duration of nitric oxide, use of anti-arrhythmias, need for shunt revision or other surgical intervention, any neurological insult and cardiac arrest.

The criteria for sepsis based on International Pediatric Sepsis Consensus Conference guidelines. The lung diseases complications included presence of atelectasis, Pneumonia, Pleural effusion or Chylothorax were evaluated by chest radiograph post-operation. Any patient with suspicion of diaphragmatic paresis or paralysis on routine chest radiograph received chest ultrasound to evaluate for diaphragmatic mobility. Neurological insult describes as deterioration in Glasgow Coma Scale, abnormal movements, or abnormal behaviors. Cardiac arrest as a cause for reintubation decided if heart rate below 60 beats per minutes and the need of cardiopulmonary resuscitation.

Pre-extubation variables collected included: duration of intubation, the administration of intravenous glucocorticoids within 24 hours of extubation, the number of sedation and inotropes infusions at the time of extubation. The laboratory data collected before extubation included arterial blood gases, white blood cell count, hematocrit, and blood urea nitrogen and serum creatinine. For all infants in the study, data collected about tissue oxygenation was assessed using near infrared spectroscopy using oxygen sensors apply to the patient skin.

Outcome data evaluated for all patients included the success or failure of extubation, intensive care unit length of stay, hospital length of stay, mortality in the hospital or after discharge and if patients lost flow up.

All patients' data were collected from Royal hospital electronic system and entered using EPI-DATA program.

Statistical analysis:

All categorical variables presented as numbers and percentages. All continuous variables are presented as the median (Q1, Q3), where Q1 is the 25th percentile and Q3 is the 75th percentile. P-values were calculated using Pearson's chi-square test or Fisher's exact test of independence for categorical variables and T-test for continuous or ordinal variables. A p-value of $<0.05$ was considered significant. Analyses were performed using SPSS version 25.

\section{Results}


During the 10 years of this study period, 146 patients included in the study. Extubation failure occurred in $18 \%(27 / 146)$ of all infants. From all, there were $55.5 \%$ (81) male patients. The median age of infants at surgery was 12 days ( 6 days, 82 days) and median weight of infants was $3.3 \mathrm{~kg}(2.9 \mathrm{~kg}, 4.1 \mathrm{~kg})$. In all, $47 \%(69 / 146)$ of the infants were ventilated before surgery and $2 \%(3 / 146)$ were on NIV. Only one infant with chronic lung disease: 5.5\% (8/146) with trisomy 21 with two other infants diagnosed with Di George syndrome. Median duration of mechanical ventilation was 2 days ( 1 day, 4 days), median intensive care unit length of stay was 6 days (4 days, 10 days), and the median hospital length of stay was 16 days (11 days, 24 days). Table 2 and 3 demonstrates intra-operative variables and post-operative complications for infants in the study. There were no differences in intra-operative variables among the two groups. Infants with post-surgeries complicated by diaphragmatic paralysis and cardiac arrest were associated with extubation failure. There was a higher need to escalate inotropes among the failed group (44\%) compared to the success group (22\%), $P=0.02$. Also, there is a trend towards a statistical significance, $P$ $=0.08$, of chest closer procedures and other procedures between the two groups.

Table 1 demonstrates Demographics and pre-existing conditions for the infants in the study. The infants in both groups were similar in age, sex, and body weight at the time of surgery. All pre-existing conditions were also similar in the two groups, except for those who were ventilated before the surgery with $66 \%$ $(18 / 27)$ from the infants with Extubation failure as presented by statistically significant P-value (0.019).

Table 2 and 3 demonstrates intra-operative variables and post-operative complications for infants in the study. There were no differences in intra-operative variables among the two groups. Infants with postsurgeries complicated by diaphragmatic paralysis and cardiac arrest were associated with extubation failure. There was a higher need to escalate inotropes among the failed group (44\%) compared to the success group ( $22 \%), p=0.02$. Also, there is a trend towards a statistical significance, $P=0.08$, of chest closer procedures and other procedures between the two groups.

Table 4 demonstrates variables in the peri-extubation period of the infants in the two groups. Duration of intubation and the labs values with oxygenation parameters show on difference between the two groups. Different systolic blood pressure (SBP) percentiles were associated with extubation failure as the lower SBP found with the group who failed extubation. Either sedation or inotropes before extubation has no difference between the two groups. 


\begin{tabular}{|llll|}
\hline \multicolumn{4}{|l|}{ Table 1. Shows the demographics and pre-existing conditions for the infants in the study } \\
\hline Risk factor & Extubation success $(n=119)$ & Extubation failure $(n=27)$ & p-value \\
\hline Age at surgery (days) & $10.0(5.0,81.0)$ & $25.0(9.0,98.0)$ & 0.706 \\
\hline Male Gender & $55 \%(66)$ & $55 \%(15)$ & 1.000 \\
\hline preterm 36-32 weeks & $9 \%(11)$ & $7 \%(2)$ & 0.953 \\
\hline Trisomy 21 & $4 \%(5)$ & $5 \%(8)$ & 0.378 \\
\hline Body weight $(\mathrm{kg})$ & $3.3(2.9,4.3)$ & $3.5(3.0,3.9)$ & 0.777 \\
\hline Ventilated before surgery & $42 \%(51)$ & $66 \%(18)$ & 0.019 \\
\hline Chronic lung disease & $1 \%(1)$ & $0 \%(0)$ & 1.000 \\
\hline $\begin{array}{l}\text { Continuous variables are summarized by the triplet of quartiles } 50 \text { th }(25 \text { th and } 75 \text { th). Categorical } \\
\text { variables are summarized as percent }(\mathrm{n}) .\end{array}$ & $\begin{array}{l}\text { The p-values are based on the t-test for continuous and ordinal data, and Pearson or Fisher's exact } \\
\text { test for categorical variables. }\end{array}$ \\
\hline
\end{tabular}


Table 2. Shows the number and percentages of various intra-operative variables for the infants in the study

\begin{tabular}{|c|c|c|c|}
\hline Risk factor & $\begin{array}{l}\text { Extubation success } \\
(\mathrm{n}=119)\end{array}$ & $\begin{array}{l}\text { Extubation failure } \\
(\mathrm{n}=27)\end{array}$ & $\mathrm{p}$-value \\
\hline Surgery duration (hr) & $1.6(1.3,2.2)$ & $2.0(1.5,2.2)$ & 0.610 \\
\hline Emergency Surgery & $56 \%(67)$ & $60 \%(20)$ & 0.128 \\
\hline Single ventricle & $66 \%(78)$ & $74 \%(20)$ & 0.498 \\
\hline Site of the shunt & & & 0.523 \\
\hline Right & $78 \%(93)$ & $67 \%(18)$ & \\
\hline Left & $12 \%(14)$ & $26 \%(7)$ & \\
\hline Central & $10 \%(12)$ & $7 \%(2)$ & \\
\hline Size of the shunt $(\mathrm{cm})$ & & & 0.245 \\
\hline 3 & $0 \%(0)$ & $4 \%(1)$ & \\
\hline 3.5 & $30 \%(36)$ & $15 \%(4)$ & \\
\hline 4 & $64 \%(76)$ & $70 \%(19)$ & \\
\hline 5 & $6 \%(7)$ & $11 \%(3)$ & \\
\hline Mid-sternotomy surgery & $69 \%(82)$ & $59 \%(16)$ & 0.368 \\
\hline Chest closer & & & 0.088 \\
\hline Close chest & $1 \%(1)$ & $7 \%(2)$ & \\
\hline Open chest & $99 \%(118)$ & $93 \%(25)$ & \\
\hline $\begin{array}{l}\text { Need of Cardiopulmonary } \\
\text { bypass }\end{array}$ & $12 \%(14)$ & $1 \%(1)$ & 0.305 \\
\hline Type endotracheal tube & & & 0.317 \\
\hline Cuffed & $3 \%(4)$ & $7 \%(2)$ & \\
\hline Uncuffed & $97 \%$ (122) & $93 \%(25)$ & \\
\hline
\end{tabular}

Continuous variables are summarized by the triplet of quartiles 50th (25th and 75 th). Categorical variables are summarized as percent $(\mathrm{n})$.

The p-values are based on the t-test for continuous and ordinal data, and Pearson or Fisher's exact test for categorical variables. 
Table 3. Shows the post-operative complications for the infants in the study

\begin{tabular}{llll} 
Risk factor & $\begin{array}{l}\text { Extubation success } \\
(\mathrm{n}=119)\end{array}$ & $\begin{array}{l}\text { Extubation failure } \\
(\mathrm{n}=27)\end{array}$ & $\begin{array}{l}\mathrm{p} \text { - } \\
\text { value }\end{array}$ \\
\hline First Lactate upon arrival to ICU & $1.4(1.0,2.3)$ & $1.5(1.2,2.0)$ & 0.412 \\
\hline Inotropic score upon arrival & $5.0(0.0,15.0)$ & $10.0(0.0,12.0)$ & 0.204 \\
\hline Need to escalate Inotropes & $22 \%(26)$ & $44 \%(12)$ & 0.027 \\
\hline $\begin{array}{l}\text { Average saturation in the first } 6 \\
\text { hours }\end{array}$ & $85.0(82.0,88.5)$ & $86.0(82.0,89.0)$ & 0.581 \\
\hline Average PaO2 in the first 6 hours & $45.0(42.0,49.0)$ & $45.0(40.0,49.0)$ & 0.403 \\
\hline Sepsis & $32 \%(38)$ & $33 \%(9)$ & 1 \\
\hline Atelectasis/ Pneumonia & $22 \%(26)$ & $37 \%(10)$ & 0.136 \\
\hline Pleural effusion & $6 \%(7)$ & $7 \%(2)$ & 0.672 \\
\hline Diaphragmatic paralysis & $4 \%(5)$ & $19 \%(5)$ & 0.02 \\
\hline Use of Nitric oxide & $3 \%(4)$ & $4 \%(1)$ & 1 \\
\hline Cardiac arrest & $4 \%(5)$ & $22 \%(6)$ & 0.006 \\
\hline Other surgery/ procedures & $14 \%(17)$ & $30 \%(8)$ & 0.085
\end{tabular}

Continuous variables are summarized by the triplet of quartiles 50th (25th and 75 th). Categorical variables are summarized as percent $(\mathrm{n})$.

The p-values are based on the t-test for continuous and ordinal data, and Pearson or Fisher's exact test for categorical variables.

Table 5 demonstrates post-extubation and outcome variables for the study patients. From all, $27 \%$ (40/146) was extubated to non-invasive ventilation and $73(106 / 146)$ were extubated to nasal cannula, with no difference between the two groups. Patients with extubation failure had longer intensive care unit length of stay and longer hospital length of stay. The mortality both before hospital discharge and after hospital discharge was similar in the two groups.

Table 6 demonstrates reason for re-intubation. Severe respiratory distress and hemodynamic instability were the two main reasons for re-intubation, where other reasons crossed interacted with each other causing failed extubation lead to re-intubation. 
Table 4. Shows the peri-extubation variables for the study.

\begin{tabular}{llll} 
Risk factor & Extubation success $(\mathrm{n}=119)$ & Extubation failure $(\mathrm{n}=27)$ & $\mathrm{p}$-value \\
\hline Duration of intubation (days) & $2.0(1.0,4.0)$ & $2.0(1.0,10.0)$ & 0.063 \\
\hline Use of steroids & $25 \%(30)$ & $30 \%(8)$ & 0.633 \\
\hline $\mathrm{Hb}$ & $13.5(12.3,14.9)$ & $12.5(12.0,13.5)$ & 0.464 \\
\hline WBC & $12.4(9.7,15.0)$ & $9.2(6.9,12.7)$ & 0.055 \\
\hline Creatinine & $44.0(37.0,51.7)$ & $40.0(32.0,46.0)$ & 0.044 \\
\hline Urea & $3.2(2.1,4.6)$ & $3.3(2.1,4.5)$ & 0.658 \\
\hline PaO2 & $43.0(40.0,47.0)$ & $45.0(42.0,49.0)$ & 0.214 \\
\hline SpO2 & $85.0(80.0,88.0)$ & $86.0(81.0,90.0)$ & 0.437 \\
\hline SBP percentile & & & 0.009 \\
\hline$<50^{\text {th }}$ & $30 \%(36)$ & $41 \%(11)$ & \\
\hline $50^{\text {th }}$ & $21 \%(25)$ & $37 \%(10)$ & \\
\hline $75^{\text {th }}$ & $24 \%(28)$ & $22 \%(6)$ & 0.650 \\
\hline $90^{\text {th }}$ & $17 \%(20)$ & $0 \%(0)$ & \\
\hline $95^{\text {th }}$ & $5 \%(6)$ & $0 \%(0)$ & \\
\hline$>95^{\text {th }}$ & $3 \%(4)$ & $0 \%(0)$ & \\
\hline CVP & $9.0(8.0,11.0)$ & $59 \%(16)$ & \\
\hline Sedation before extubation & $57 \%(68)$ & $(10)$ & \\
\hline Inotropes before Extubation & $31 \%(37)$ & 000 \\
\hline
\end{tabular}

Continuous variables are summarized by the triplet of quartiles 50th (25th and 75 th). Categorical variables are summarized as percent $(\mathrm{n})$.

The p-values are based on the t-test for continuous and ordinal data, and Pearson or Fisher's exact test for categorical variables. 
Table 5. Shows the post-extubation and outcome variables.

\begin{tabular}{llll} 
Risk factor & Extubation success $(\mathrm{n}=119)$ & Extubation failure $(\mathrm{n}=27)$ & p-value \\
\hline Extubated to & & & 0.813 \\
\hline NIV & $27 \%(32)$ & $30 \%(8)$ & \\
\hline NC & $73 \%(87)$ & $70 \%(19)$ & 0.002 \\
\hline ICU length of stay (days) & $5.0(3.0,8.0)$ & $12.0(9.0,24.0)$ & 0.002 \\
\hline Hospital length of stay (days) & $14.0(10.0,20.0)$ & $25.0(18.0,49.0)$ & 0.163 \\
\hline Hospital death & $9 \%(10)$ & $19 \%(5)$ & 0.690 \\
\hline Death after discharge & $9 \%(10)$ & $4 \%(1)$ & 0.061 \\
\hline Lost Follow up & $11 \%(13)$ & $26 \%(7)$ &
\end{tabular}

Continuous variables are summarized by the triplet of quartiles 50th (25th and 75th). Categorical variables are summarized as percent $(\mathrm{n})$.

The p-values are based on the t-test for continuous and ordinal data, and Pearson or Fisher's exact test for categorical variables.

\begin{tabular}{|ll|}
\hline \multicolumn{2}{|l|}{ Table 6. Shows the reason for re-intubation for patients with extubation failure } \\
\hline Reason for re-intubation & Extubation failure $(\mathrm{n}=27)$ \\
\hline Hypoxia & $22 \%(6)$ \\
\hline Hypercarbia & $11 \%(3)$ \\
\hline Respiratory depression & $11 \%(3)$ \\
\hline Severe respiratory distress & $44 \%(12)$ \\
\hline Hemodynamic instability & $44 \%(12)$ \\
\hline Stridor & $7 \%(2)$ \\
\hline
\end{tabular}

\section{Discussion}

This is the first national epidemiological study in Oman investigates predictors, incidence, and outcomes of extubation failure in infants post BT shunt. This study defined extubation failure post BT shunt as the 
need for re-intubation within 72 hours post extubation. This definition is variable among many studies as some are extending the re-intubation over 96 hours, others are limiting the period to 48 hours (20). We used the time frame of 72 hours, which is quite satisfactory because this incidence might evolve slowly. However, Laudato, $\mathrm{N}$ et al observed that extubation failure beyond 72 hours is uncommon (19).

As shown in our study, the incidence of extubation failure was $18 \%(27 / 146)$. This proportion was less than the $27 \%(15 / 55)$ reported by Gupta et.al (20). This variation could be attributed to inconsistency in the definition of extubation failure and sample size. Gupta et al defined the infant with extubation failure as those who need positive pressure ventilation within 96 hours of an extubation attempt. Another important factor is the heterogeneity of the cases included. Mastropietro et al., reported extubation failure rate of $12 \%$ in neonates who underwent cardiac (21).

To our best of knowledge, few studies evaluated the predictors of extubation failure post MBT shunt. We observed higher risk for extubation failure in patients who required ventilation before the surgery. This might be suggested by higher disease burden on those patients. A recent study conducted by Gaies et.al identified the prolonged mechanical ventilation prior to extubation as the only independent risk factor predictive of extubation failure (22), although the duration of intubation did not reach clinical significance (0.063), but it was higher in those who failed extubation.

Mastropietro et al., found that the use of uncuffed endotracheal tubes is associated with significant rates of extubation failure (21). Not surprisingly, this factor was not clinically significant in our study, as the trend of using cuffed ET tubes are uncommon in our institution, with majority of our study population, have been intubated using uncuffed ET tubes, so we cannot study their effect on extubation failure.

Weaning from ventilation requires effective cardiovascular and respiratory capacity, and major impairment subsequently result in ventilation weaning failure. Reviewing the post-operative parameters, we found that the escalation of inotropes is significant predictor for the extubation failure, though the inotropic score did not reflect this association, because the escalation was in the dose of inotropes but not the number of inotropic drugs used. In addition, surgeries complicated by cardiac arrest and diaphragmatic paralysis associated with higher rate of extubation failure, whereas other complications like pneumonia, pleural effusion, sepsis and use of nitric oxide did not appear to have a major role.

Circumstances pre extubation were optimized in all infants, according to the extubation criteria applied for infants admitted in intensive care units in Royal hospital, which reflects weak association of labs studies, steroid use, sedation and inotropes to the incidence of extubation failure.

Consistent with previous study, Gupta et al., the causes for extubation failure are multi-factorial (20). In our study, majority occurred as a result of severe respiratory distress and hemodynamic instability, with minority happened due to respiratory failure, respiratory depression and stridor. According to Harkel, van der Vorst, Hazekamp and Ottenkamp, the main reasons for extubation failure were upper airway obstruction and cardiorespiratory failure (23). 
Extubation failure is associated with longer intensive care unit and hospital admission. However, the overall mortality was similar in both groups, which is partially consistent with Gupta et al. study as they found extubation failure is not associated with increased hospital length of stay or mortality (20).

\section{Limitations}

The retrospective character of our study is a main limitation, because of missing data in some parameters. Nevertheless, we think that the number of patients collected did not allow drawing good conclusions in terms of risk factors of extubation failure. More sample size is necessary in our population and that would allow the results of our study to be generalized.

\section{Conclusion}

Modified BT shunt is common cardiac surgery done in Oman, with low percentage of extubation failure, observed mostly in those patients who required prolonged mechanical ventilation and escalation of inotropes, and in those complicated by cardiac arrest and diaphragmatic palsy. Differences in extubation failure rates across hospitals highly impacted by the hospital perioperative and intensive care practices. Subsequently, lower incidence rate for extubation failure, might indicate higher quality performance of our institution.

\section{Declarations}

- Ethical Approval and Consent to participate: ethical approval form is attached in PDF file

- Consent for publication: No consent was needed from the parents as this a single retrospective cohort study and the results will be anonymous.

\section{- Availability of supporting data: Nill}

- Competing interests: No competing interest.

- Funding: No fund was received to conduct this study.

- Authors' contributions: The idea was of the corresponding author but all authors contributed to all stages of the research as the two co-authors are resident under Oman Medical Specialty Board.

- Acknowledgements: Oman Medical Specialty Board.

\section{References}

1. Cox AC, Piedmonte M, Drummond-Webb JJ, et al. Factors associated with prolonged mechanical ventilation in children following cardiothoracic surgery. Crit Care Med 2000; 28: A75. 
2. Kanter RK, Bove EL, Tobin JR, et al. Prolonged mechanical ventilation of infants after open heart surgery. Crit Care Med 1986; 14: 211-214.

3. Corno AF, Hurni M, Payot M, von Segesser LK. Modified Blalock-Taussig shunt with compensatory properties. Ann Thorac Surg. 1999 Jan. 67(1):269-70.

4. 15- Singh SP, Chauhan S, Choudhury M, Malik V, Talwar S, Hote MP, et al. Modified Blalock Taussig shunt: Comparison between neonates, infants and older children. Ann Card Anaesth2014; 17:191-7.

5. Petrucci O, O’Brien SM, Jacobs ML, Jacobs JP, Manning PB, Eghtesady P. Risk factors for mortality and morbidity after the neonatal Blalock-Taussig shunt procedure. Ann Thorac Surg 2011; 92:642-51.

6. McKenzie ED, Khan MS, Samayoa AX, Vener DS, Ishak YM, Santos AB, et al. The Blalock-Taussig shunt revisited: A contemporary experience. J Am Coll Surg 2013; 216:699-704.

7. Punkaj Gupta, Rachel McDonald, Sunali Goyal, Jeffrey M. Gossett, Michiaki Imamura, Amit Agarwal, Warwick Butt, Adnan T. Bhutta. Extubation failure in infants with shunt-dependent pulmonary blood flow and univentricular physiology. Cardiology in the Young (2014), 24, 64-72.

8. Harrison AM, Cox AC, Davis S, Piedmonte M, Drummond- Webb JJ, Mee RB. Failed extubation after cardiac surgery in young children: prevalence, pathogenesis, and risk factors. Pediatr Crit Care Med 2002; 3: 148-152.

9. Khan N, Brown A, Venkataraman ST. Predictors of extubation success and failure in mechanically ventilated infants and children. Crit Care Med 1996; 24: 1568-1579.

10. Tobin MJ, Perez W, Guenther SM, et al. The pattern of breathing during successful and unsuccessful trials of weaning from mechanical ventilation. Am Rev Respir Dis 1986; 134: 1111-1118.

11. Freely TW, Hedley-Whyte J. Weaning from controlled ventilation and supplemental oxygen. $\mathrm{N}$ Engl J Med 1975; 292: 903-906.

12. Balsan MJ, Jones JG, Watchko JF, et al. Measurements of pulmonary mechanics prior to elective extubation of neonates. PediatrPulmonol 1990; 9: 238-243.

13. Johnston C, de Carvalho WB, Piva J, Garcia PC, Fonseca MC. Risk factors for extubation failure in infants with severe acute bronchiolitis. Respir Care 2010; 55: 328-333.

14. Laussen PC, Roth SJ. Fast tracking: efficiently and safely moving patients through the intensive care unit. Prog PediatrCardiol 2003; 18: 149-158.

15. Kloth R, Baum V. Very early extubation in children after cardiac surgery? Crit Care Med 2002; 30: 787-791.

16. Vricells LA, Dearani JA, Grundy SR, et al. Ultra-fast track in elective congenital heart surgery. Ann Thorac Surg 2000; 69: 865-871.

17. Bandla HP, Hopkins RL, Beckerman RC, Gozal D. Pulmonary risk factors compromising postoperative recovery after surgical repair for congenital heart disease. Chest 1999; 116: 740-747.

18. Schuller JL, Bovill JG, Nijveld A, Patrick MR, Marcelletti C. Early extubation of the trachea after open heart surgery for congenital heart disease. A review of 3 years' experience. Br J Anaesth 1984; 56: 
1101-1108.

19. Laudato, N., Gupta, P., Walters, H., Delius, R. and Mastropietro, C., 2015. Risk Factors for Extubation Failure Following Neonatal Cardiac Surgery*. Pediatric Critical Care Medicine, 16(9), pp.859-867.

20. Gupta, P., McDonald, R., Goyal, S., Gossett, J., Imamura, M., Agarwal, A., Butt, W. and Bhutta, A., 2013. Extubation failure in infants with shunt-dependent pulmonary blood flow and univentricular physiology. Cardiology in the Young, 24(1), pp.64-72.

21. Mastropietro, C., Cashen, K., Grimaldi, L., Narayana Gowda, K., Piggott, K., Wilhelm, M., Gradidge, E., Moser, E., Benneyworth, B. and Costello, J., 2017. Extubation Failure after Neonatal Cardiac Surgery: A Multicenter Analysis. The Journal of Pediatrics, 182, pp.190-196.e4.

22. Gaies, M., Tabbutt, S., Schwartz, S., Bird, G., Alten, J., Shekerdemian, L., Klugman, D., Thiagarajan, R., Gaynor, J., Jacobs, J., Nicolson, S., Donohue, J., Yu, S., Pasquali, S. and Cooper, D., 2015. Clinical Epidemiology of Extubation Failure in the Pediatric Cardiac ICU. Pediatric Critical Care Medicine, 16(9), pp.837-845.

23. Harkel, A., van der Vorst, M., Hazekamp, M. and Ottenkamp, J., 2005. High Mortality Rate after Extubation Failure after Pediatric Cardiac Surgery. Pediatric Cardiology, 26(6), pp.756-761.

\section{Figures}




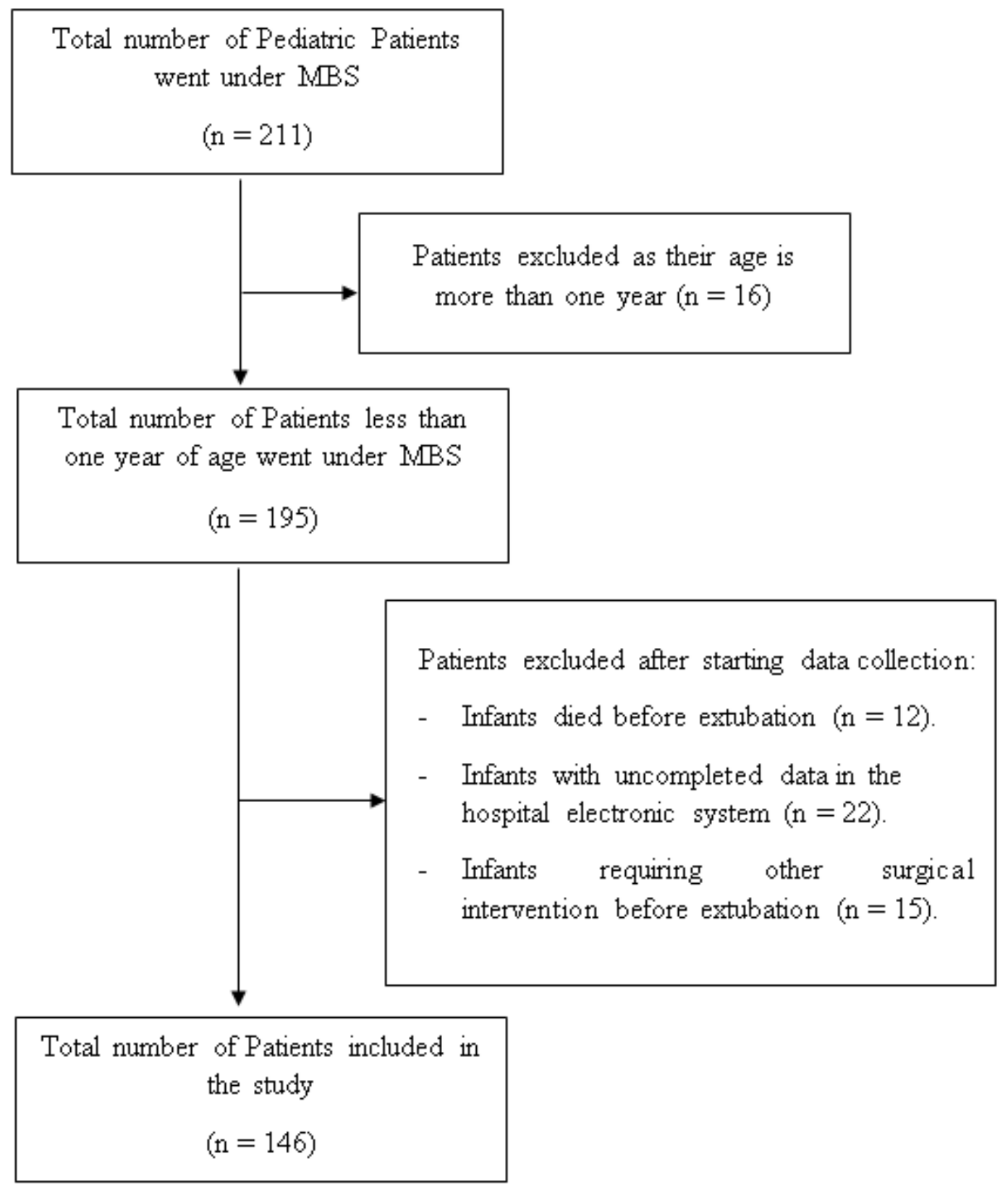

\section{Figure 1}

\section{Exclusion criteria}

